\title{
In Vitro Characterization of the Efficacy and Safety Profile of a Proprietary Ajuga turkestanica Extract
}

\author{
José M. Zubeldia ${ }^{*}$, Aarón Hernández-Santana ${ }^{1}$, Miguel Jiménez-del-Rio ${ }^{1}$, \\ Verónica Pérez-López ${ }^{1}$, Rubén Pérez-Machín ${ }^{2}$, José Manuel García-Castellano ${ }^{3}$ \\ ${ }^{1}$ Polinat S. L. Taibique 4, Polígono Industrial Las Majoreras, Las Palmas, Spain \\ ${ }^{2}$ Molecular Oncology Group (G-OncoMol) Research Unit, University Hospital of Gran Canaria, \\ Canary Health and Research Foundation Barranco de la Ballena, Las Palmas, Spain \\ ${ }^{3}$ Department of Orthopaedic Surgery, Complejo Hospitalario Universitario Insular, Las Palmas, Spain \\ Email: *jose@polinat.com
}

Received September 12, 2012; revised October 18, 2012; accepted November 3, 2012

\begin{abstract}
Ajuga turkestanica, an herbaceous flowering species in the mint family, has been traditionally used in Turkey and Uzbekistan for heart disease, muscle aches and stomach problems. Due to its high levels of phytoecdysteroids (particularly the characteristic C-11-hydroxylated Turkesterone), anabolic properties have also been reported. The aim of our study was to screen for early signs of efficacy and safety of a proprietary Ajuga turkestanica extract (ATE) using in vitro models. $\mathrm{C}_{2} \mathrm{C}_{12}$ mouse myotube cell line was used to study potential effects on viability and gene modulation. Cell viability was evaluated with different concentrations $[0.2-200 \mathrm{ppm}(\mathrm{mg} / \mathrm{L})]$ of ATE. Gene modulation was assessed by quantitative polymerase chain reaction (qRT-PCR) after $6 \mathrm{~h}$ incubation (ATE vs. the androgenic anabolic steroid methandrostenolone). Total androgenic activity was measured using the A-SCREEN bioassay. Ultra-high performance liquid chromatography analysis showed good correlation between the phytochemical profile of the native plant and our ATE. $\mathrm{C}_{2} \mathrm{C}_{12}$ mouse myotube cells treated with ATE experienced no significant loss of viability (concentrations $0.2-200$ ppm, 1 - 24 hs, $p>0.05)$. qRT-PCR array analysis showed significant $(\mathrm{p}<0.05)$ down regulation of Caspase-3 (2-fold) and Myostatin (4-fold). The extract showed no androgenic activity within the dose range used. Our results indicate the potential for an ATE to support muscle mass without typical androgenic side effects of synthetic anabolic drugs.
\end{abstract}

Keywords: Ecdysteroids; Ajuga turkestanica; Turkesterone; Caspase 3; Myostatin; Androgenic Activity; Sarcopenia

\section{Introduction}

The genus Ajuga (Labiatae) is comprised of more than 40 species widely distributed in temperate regions of both hemispheres and contains at least three classes of potentially bioactive compounds: clerodane diterpenes, phytoecdysteroids and iridoid glycosides. Ajuga turkestanica (Regel) Briq is a perennial herb growing mainly in Central Asia known as a rich source of bioactive substances and used by local people to treat heart diseases, muscle and stomach aches [1]. With regards to phytoecdysteroids several bioactive compounds have been isolated including turkesterone, 20-hydroxyecdysone (20$\mathrm{HE}$ ), cyasterone, cyasterone 22-acetate, ajugalactone, ajugasterone $\mathrm{B}, \alpha$-ecdysone and ecdysone 2,3-monoacetonide [2,3]. A characteristic feature of Ajuga turkestanica is the presence of the C11-hydroxylated turkeste-

*Corresponding author. rone, which has not been observed in other species of the same genus [4].

Ecdysteroids are polyhydroxylated ketosteroids with long carbon side chains. These steroid hormones control moulting and reproduction in arthropods, but their role in plants is less well known as they do not elicit any of the classical plant hormone responses [5]. Plants may use ecdysteroids as a chemical defense against insects by disrupting their hormonal balance and moulting process [6]. The discovery of these steroid molecules in 1966 in several plant species led to their availability in large amounts for pharmacologic studies in search of safer more specific insecticides. While showing no signs of toxicity, ecdysteroids had other possible beneficial effects that could support their use in folk medicine such as immunomodulation, antiarrythmic, hepatoprotective, or antidiabetes effects [7-10].

Ecdysteroids are structurally different from mammal- 
ian steroids, and they are not expected to bind to vertebrate steroid receptors. However, anabolic effects have been reported in vertebrates: increased growth in mice, rats, sheep, or pigs, and increased physical performance without training in rats with increased synthesis of myofibrillar proteins [11].

The potential for any substance to increase protein synthesis in muscle by-passing secondary effects common with steroid synthetic drugs may be an attractive approach for important health issues such as sarcopenia, a condition in which subjects have progressive generalized loss of skeletal muscle mass and function. It has been associated with adverse outcomes such as falls, mobility limitations, incident disability, and fractures in the elderly [12]. It is also associated with insulin resistance in both non-obese and obese individuals and abnormal blood glucose levels in obese individuals, especially in those younger than 60 years of age [13]. Finally, sarcopenia plays a key role in the development of cachexia, a syndrome occurring at terminal stages of cancer, chronic heart or kidney failure, or AIDS [14]. Proposed treatments include testosterone supplementation, which would require close monitoring of androgenic side effects such as prostate hypertrophy [15].

The aim of our study was to initially screen a proprietary Ajuga turkestanica extract (ATE), rich in ecdysteroids for early signs of efficacy (increase/protection of muscle mass) and safety (lack of androgenic activity).

\section{Materials and Methods}

\subsection{Chemicals and Materials}

HPLC grade acetonitrile and methanol were purchased from Merck (Spain). Water was purified and deionized by a Milli-Q ultrapure water system. Turkesterone and 20hydroxyecdysone (20-HE) reference standards were obtained from Chromadex (Irvine, USA). Methandrostenolone, a commercially available synthetic anabolic steroid, and $17 \beta$-Estradiol (E2) were purchased from Sigma-Aldrich (Spain). Methyltrienolone (R1881), a nonme- tabolizable synthetic anabolic steroid, was provided from Perkin Elmer (Spain).

\subsection{Plant Extraction}

Ajuga turkestanica was collected in Uzbekistan. The dried whole plant $(1 \mathrm{~kg})$ was extracted in a percolator at room temperature using $10 \mathrm{~L}$ of $85 \%$ ethanol in water for $2 \mathrm{hs}$. The liquid fraction was removed and the whole process was repeated. The two liquid fractions $(20 \mathrm{~L})$ were combined and ethanol was removed in vacuo before freeze-drying (Telstar Cryodos benchtop freezedrier). Samples were vacuum sealed in plastic bags and stored at room temperature inside a dessicator.

\subsection{Chromatography}

Ajuga turkestanica whole dried plant (finely ground) or powdered extract $(0.1 \mathrm{~g})$ was diluted in methanol $(25 \mathrm{ml})$ and sonicated for $15 \mathrm{~min}$ at room temperature. The solution was filtered through a $0.2 \mu \mathrm{m}$ syringe filter (Micron Analytical, Spain) before analysis by ultra high performance liquid chromatography (UPLC). UPLC analysis was performed on a Waters Acquity H-Class UPLC system coupled to a photodiode array detector (PDA). Separation was carried out on an Acquity C18 BEH column (Waters, $100 \times 2.1 \mathrm{~mm}, 1.7 \mu \mathrm{m}$ ). The mobile phase consisted of ultrapure water (A) and acetonitrile (B). The following linear gradient was used: $0-5 \mathrm{~min}, 10 \%-50 \%$ B; 5 - $6 \min , 50 \%-100 \%$ B, $6-8 \min , 100 \%$ B. Each run was followed by an equilibration period of $2 \mathrm{~min}$. The flow rate was $0.5 \mathrm{ml} / \mathrm{min}$ and the injection volume 1 $\mu \mathrm{L}$. The column temperature was $50^{\circ} \mathrm{C}$ and the detection wavelength was set to $245 \mathrm{~nm}$.

\subsection{Gene Expression Study}

A mouse skeletal muscle cell line, $\mathrm{C}_{2} \mathrm{C}_{12}$ (American Type Culture Collection, UK), was cultured in Dulbecco's Modified Eagle's Medium (DMEM) with high glucose (Thermo Fisher Scientific, Spain) supplemented with $10 \%$ fetal bovine serum (Lonza Group, Switzerland), 2 $\mathrm{mM}$ glutamine, 100 units $/ \mathrm{ml}$ penicillin and $100 \mu \mathrm{g} / \mathrm{ml}$ streptomycin. Cells between passages 3 and 10 were seeded at a density of 10,000 cells per $\mathrm{cm}^{2}$. Cells were grown for 48 hs until they reached $80 \%$ - 90\% confluence. To induce myogenic differentiation, the medium was replaced with differentiation medium, DMEM supplemented with $2 \%$ horse serum (PAA Laboratories, Austria) $[11,16]$. After 10 days the myoblasts had fused into multinucleated myotubes. Cells were maintained at $37^{\circ} \mathrm{C}$ in a humidified $5 \% \mathrm{CO}_{2}$ incubator and medium was changed every other day.

Cell viability after ATE treatment was determined using the Presto Blue cell viability kit (Invitrogen, Spain) following the manufacturer's instructions. $\mathrm{C}_{2} \mathrm{C}_{12}$ cells were plated and differentiated to myotubes into 96-well plates. After differentiation, the culture medium was replaced with DMEM containing various concentrations of ATE $(0.2-200$ ppm) for 1, 3, 6 and 24 hours. Before Presto Blue kit reagents were added, the medium was removed and cells were washed with PBS. The cells were incubated with Presto Blue for $20 \mathrm{~min}$ at $37^{\circ} \mathrm{C}$. Fluorescence was measured on a MX3005P Q-PCR System (Agilent Technologies, Spain) using a Cy3 filter set on plate read mode.

For RNA extraction, $\mathrm{C}_{2} \mathrm{C}_{12}$ cells were plated and differentiated to myotubes into 12-wells plates. After differentiation, cells were incubated with $20 \mathrm{ppm}$ ATE (approx. $1 \mu \mathrm{M}$ total ecdysteroids) or $1 \mu \mathrm{M}$ methandros- 
tenolone for $6 \mathrm{~h}$. RNA was then extracted using an All Prep RNA/Protein Kit (Qiagen, Spain). Total RNA was quantified using a fluorometric method with Quant-iT kit (Invitrogen, Spain). RNA was stored at $-80^{\circ} \mathrm{C}$ until further use. cDNA was reverse-transcribed from the RNA extract using $\mathrm{RT}^{2}$ First Stand cDNA kit and we used a $\mathrm{RT}^{2}$ Profiler PCR Array to analyze a panel of 84 genes involved in skeletal muscle development and disease (Qiagen, Spain). Quantitative real-time RT-PCR was carried out using a SYBR-Green/ROX detection in a MX3005P Q-PCR System. Samples were heated at $95^{\circ} \mathrm{C}$ for $10 \mathrm{~min}$, followed by a second stage composed of 15 sec at $95^{\circ} \mathrm{C}, 1 \mathrm{~min}$ at $60^{\circ} \mathrm{C}$ which was repeated 40 times and third stage for dissociation curve composed of $1 \mathrm{~min}$ at $95^{\circ} \mathrm{C}, 30 \mathrm{sec}$ at $55^{\circ} \mathrm{C}$ and $30 \mathrm{sec}$ at $95^{\circ} \mathrm{C}$.

To analyze the PCR-array data, an MS-Excel sheet with macros was downloaded from the manufacturer's website (http://www.sabiosciences.com). This program calculated relative gene expression and statistical significance.

\subsection{Androgenic Study}

MCF-7-AR1 cells were kindly provided by Nicolas Olea from Granada University, Spain. The MCF-AR1 cells result from stably transfected $\mathrm{MCF}-7$ human breast cancer cell with a full human AR 27. The MCF-7-AR1 cell line was grown routinely in a humidified atmosphere of $5 \% \mathrm{CO}_{2}$ at $37^{\circ} \mathrm{C}$ in Dulbecco's modified Eagle's Medium (DMEM) without phenol red containing 10\% fetal bovine serum (FBS) supplemented with $2 \mathrm{mM}$ glutamine, 100 units $/ \mathrm{ml}$ penicillin, $100 \mu \mathrm{g} / \mathrm{ml}$ streptomycin, $15 \mathrm{mM}$ HEPES and $4.2 \mathrm{mM}$ sodium bicarbonate (FBS-DMEM) (Lonza Group, Switzerland). Cells become proliferative quiescent when transferred into the same Culture medium but supplemented with $10 \%$ charcoal-dextran-treated FBS (CD-FBS, steroid free) (Thermo Fisher Scientific, Spain) instead of FBS. The CD-FBS-DMEM medium was used as experimental medium. MCF-7-AR1 cells proliferate maximally in experimental medium plus 100 pM E2, and respond to androgens by decreasing their proliferation rate in a dose-dependent fashion.

To test for the potential cytotoxicity of AE on MC7AR1, cells were trypsinized, counted and plated into 96-wells plates (NUNC) at seed density of 4000 cell per well in FBS-DMEM. After 24 hs to allow attachment, cells were treated with FBS-DMEM alone and with FBS-DMEM in the presence of a range of ATE concentrations. After incubation for five days, the FBS-DMEM was gently aspirated and the cells were trypsinized. Trypan blue exclusion test was used to count viable cells and non-viable cells. The method stains selectively non-viable cells. Briefly, a suitable cell suspension was given into a tube and $0.4 \% \mathrm{w} / \mathrm{v}$ of trypan blue stain was added. After mixing, solution was incubated $5 \mathrm{mins}$ at room temperature. Cells were finally counted in a TC10 automated cell counter (BioRad Laboratories, Spain).

The A-Screen bioassay compares the cell number of similar inocula of MCF-7-AR1 cells growing in CDFBS-DMEN in the absence of any estrogen and androgens (negative control), in the presence of $100 \mathrm{pM}$ of E2 (estrogen control) and $100 \mathrm{pM}$ of E2 plus a range of ATE concentrations. MCF-7-AR1 were trypsinized and seeded into 96-wells plate (Nunclon delta) at concentration of $6000 \mathrm{cell} /$ well in experimental medium. After 24 hours to allow attachment, experimental medium with $100 \mathrm{pM}$ of E2 containing the various dilutions ATE (0.1 to 100 PPM) was added into each well. Positive (100 pM E2) and negative control (CD-FBS-DMEM), as well as plant extract doses were tested six-fold. In addition, an androgen reference curve made with R1881 or methandrostenolone was set up as positive control in every experiment. After $120 \mathrm{hs}$, the assay was finished by gently removing the experimental medium and the addition of ice-cold $10 \%$ Thricloroacetic acid (wt/vol). The plates were left on ice for $30 \mathrm{mins}$, then rinsed gently 3 times with water and allowed to air dry. Cells were then stained with $0.4 \%$ sulforhodamine B (SRB) in 1\% ( vol/col) acetic acid for 20 mins. The bound dye was solubilized with Tris-base $\mathrm{pH}$ 10.6. After short shaking, absorbance was read in a MW plate reader (Biotek) at $492 \mathrm{~nm}$ subtracting the background measurement at $620 \mathrm{~nm}$. It has been established previously that there is a direct linear relationship between cell number and the absorbance values of the Tris-SRB solution. Experimental readings were in the lineal range of the standard curve (Data not shown).

\section{Results}

The most abundant ecdysteroids in the A. turkestanica extract were quantified with UPLC-PDA. Figure 1 shows the chemical structures and the chromatographic separation of the main bioactive compounds typically found in Ajuga turkestanica plant extracts and the powder extract used in this study. The ATE powder contained approximately $0.69 \%(\mathrm{w} / \mathrm{w})$ turkesterone and $1.30 \%(\mathrm{w} / \mathrm{w}) 20$ HE. No significant difference was observed between the Ajuga turkestanica plant and the corresponding powder extract, indicating that the phytochemical profile of the main bioactive compounds does not change during the extraction and preparation process. Preservation of the native constituents in the plant is essential prior to any biological testing.

To evaluate potential cytotoxicity, myotubes were treated with ATE powder at concentrations from 0.2 to $200 \mathrm{ppm}(\mathrm{mg} / \mathrm{L})$ for up to $24 \mathrm{hs}$ and cell viability was evaluated using the Presto Blue cell viability kit. This reagent kit is a resazurin-based assay, where resazurin is converted to the fluorescent product resorufin by metabolically active cells and measured quantitatively [17]. 
This transformation of non-fluorescent resazurin to fluorescent resorufin is the basis for the use of this fluorometric indicator for the determination of cell viability. We did not see any significant loss of cell viability for the range of concentrations and treatment period used in this study (Figure 2(a), p > 0.05).

Our ATE showed a 2-fold downregulation of caspase-3 in myotubes while the androgenic anabolic steroid methandrostenolone downregulated caspase- 3 but to a lesser extent compared to the ATE ( $<2$-fold). Myotubes treated for 6 hs with ATE showed a 4-fold down-regulation of Myostatin. Methandrostenolone treatment also downregulated myostatin to a lesser extent $(<2$-fold) (Figure 2(b), $\mathrm{p}<0.05)$.

Since androgenic activity is ultimately based on cell number end-point, it was necessary to establish whether any decrease in proliferation could be associated with a cytotoxic effect of the extract rather than AR agonist action before the A-Screen was performed. Trypan blue dye exclusion assay was used to examine ATE-mediated cytotoxicity (expressed as non-viable cells) and to assess cell viability upon exposure to ATE in complete medium (FBS-DMEM). ATE treatment reduced both total cell number and viability of MCF7-AR1 cells in a dose-dependent manner (Figure 3). The results show that ATE inhibits MCF7-AR1 cell viability at very high doses (200 and $600 \mathrm{ppm}$ ) by inducing both a cytotoxic cell response and reducing the number of viable cells. Based on the above, the concentration of ATE used in the A-Screen assay was limited to a range of $0.1-100 \mathrm{ppm}$.

Results of the A-Screen test are shown in Figure 4. The synthetic androgen methyltrienolone (R1881) was used as the reference compound ( $\mathrm{Ca}$, positive control) and a dose-response curve showed that R1881 inhibited

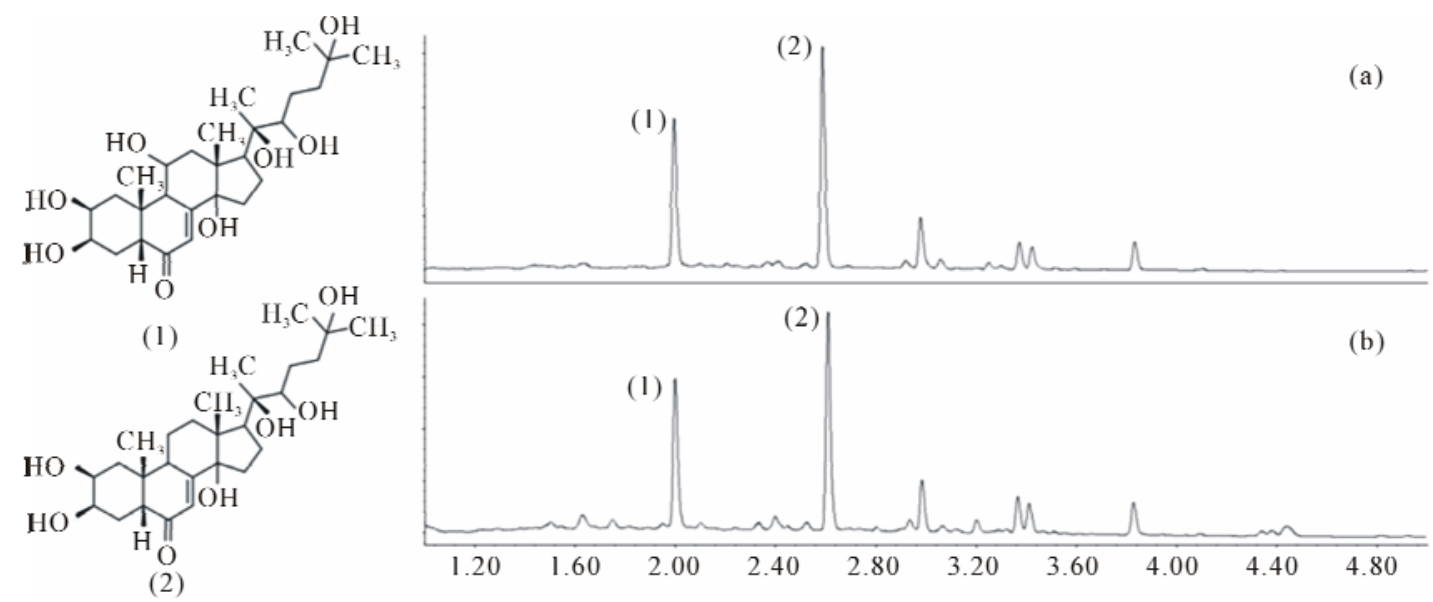

Figure 1. Chemical structures of the main bioactive compounds in Ajuga turkestanica: (1) turkersterone; and (2) 20-HE. UPLC chromatograms of (a) Ajuga turkestanica whole plant; and (b) the corresponding freeze-dried powder extract (ATE) measured at $245 \mathrm{~nm}$.

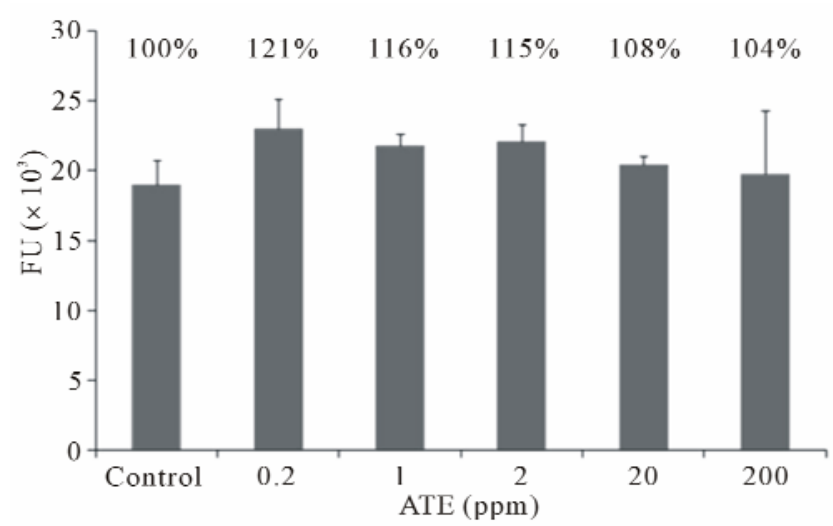

(a)

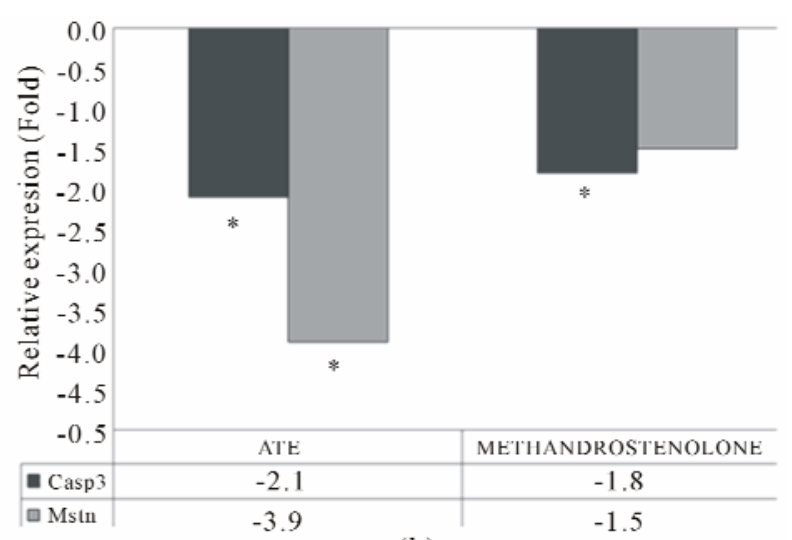

(b)

Figure 2. (a) Effect of $\mathrm{AE}$ treatment on $\mathrm{C}_{2} \mathrm{C}_{12}$ muscle cell viability. Cells were cultured with media containing different concentrations of ATE $(0.2-200 \mathrm{ppm})$ for $24 \mathrm{hs}(\mathrm{n}=3)$. Results are expressed in fluorescence units (FU) and percentage of viability, calculated using the following equation: (FU treated/FU control) $\times 100$; (b) Effect of ATE and methandrostenolone on Caspase-3 (Casp-3) and myostatin (Mstn) gene expression levels in $\mathrm{C}_{2} \mathrm{C}_{12}$ muscle cells. Test groups were treated with 20 ppm of ATE for 6 hours $(n=3)$. " $p<0.05$. 


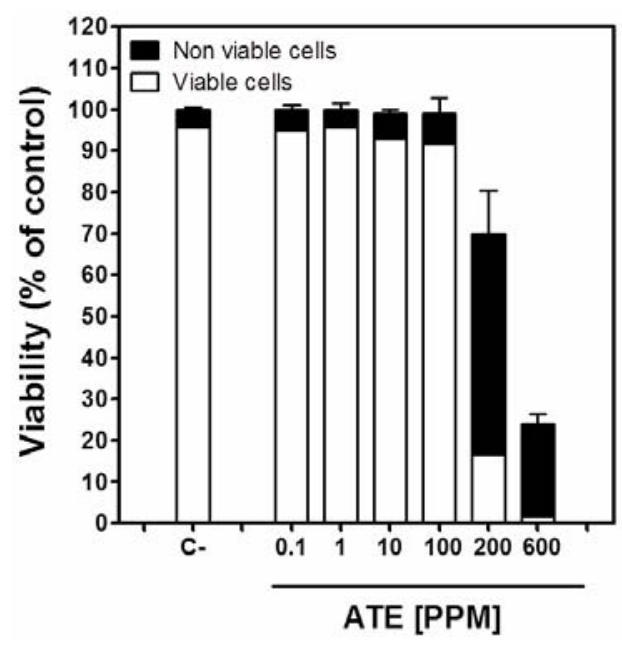

Figure 3. Effect of ATE on cell viability of MCF-7AR1 determined by trypan blue dye exclusion assay. Cells were grown for 5 days with FBS-DMEM in the presence of a range of $\mathrm{AE}$ concentrations (0.1 - 600 ppm). C-: FBSDMEM only. Results are showed as fraction of viable and nonviable cells and are expressed as percentage of the negative control total (viable and non viable) cell number.

cell proliferation at very low concentrations (Figure 4(a)), IC50 $=20 \mathrm{pM}$ ). Methandrostenolone also inhibited cell proliferation at higher concentrations (Figure 4(b), IC50 $=350 \mathrm{pM}$ ). The addition of ATE at a range of concentrations $(0.1-100 \mathrm{ppm})$ to the culture media in the presence of E2 did not show a significant proliferative inhibition compared with the control (MCF7-AR1 cells plus E2) at doses up to $100 \mathrm{ppm}$ (Figure 4(c)).

\section{Discussion}

The $\mathrm{C}_{2} \mathrm{C}_{12}$ mouse cell line is a well-established in vitro model for skeletal muscle studies [18]. $\mathrm{C}_{2} \mathrm{C}_{12}$ myoblasts may be readily differentiated into multinucleated myotubes under controlled conditions, and these cells behave in many ways like skeletal muscle fibers, contracting when stimulated and expressing characteristic muscle proteins $[19,20]$. In this context, $\mathrm{C}_{2} \mathrm{C}_{12}$ myotubes were used to study cell viability and changes in modulation of genes associated with muscle skeletal, muscle development and disease upon treatment with our ATE.

Evaluation of the molecular pathways involved in the putative anabolic effect of the ecdysteroids present in the ATE suggests two possible pathways. During muscle wasting caspase-3 activation and the ubiquitin proteasome system (UPS) act synergistically to increase the degradation of muscle proteins. Activation of the former is required to convert actomyosin and myofibrils into substrates of the UPS. Caspase-3 cleaves specific $19 \mathrm{~S}$ proteasome subunits in $\mathrm{C}_{2} \mathrm{C}_{12}$ muscle cells with a cellspecific activity. Caspase-3 cleaves different subunits in myoblasts and myotubes hence intervening in cell dif-

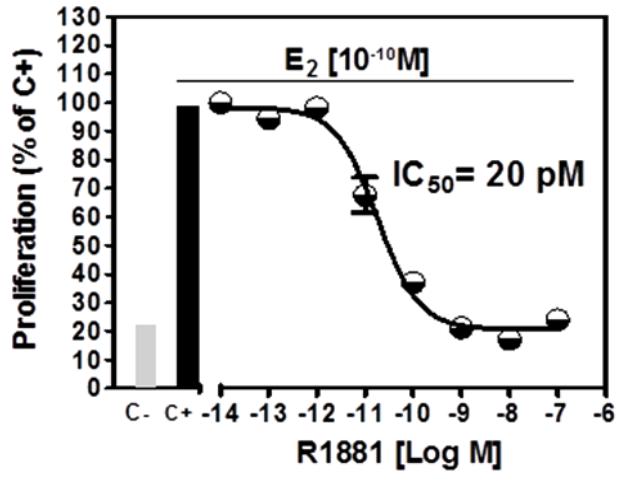

(a)

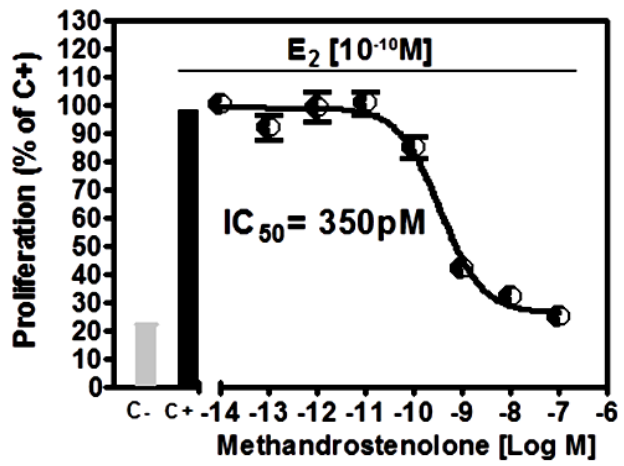

(b)

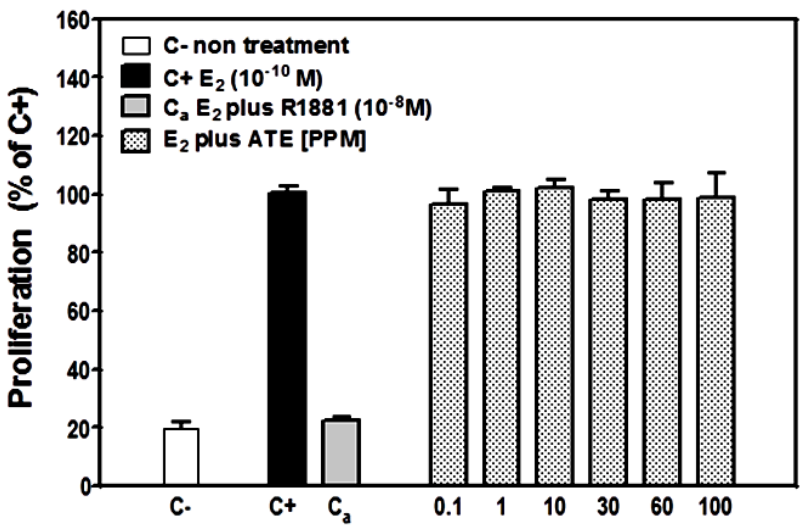

(c)

Figure 4. Androgenic activity bioassay (A-Screen): Doseresponse curve to (a) methyltrienolone (R1881) and (b) methandrostenolone by MCF7-AR1 cells in the presence E2. (c) Proliferative response of E2 treated MCF7-AR1 cells to ATE in a range of concentrations (0.1 - 100 ppm). C-, nontreated; C+, E2; Ca, E2 plus R1881.

ferentiation or muscle wasting [21]. Recently, Bhatnagar and colleagues have shown that adding a caspase- 3 inhibitory peptide to myotube cultures resulted in inhibittion of tumor necrosis factor-like weak inducer of apoptosis (TWEAK) induced loss of myosin heavy chain and myotube diameter [22]. Our ATE showed a 2-fold downregulation of caspase- 3 in myotubes supporting its potential to protect muscle form wasting, as opposed to methan- 
drostenolone which downregulated caspase-3 to a lesser extent $(<2$-fold).

Myostatin is mostly expressed in skeletal muscle and normally functions as a negative regulator of muscle growth. Upon the binding to activin type IIB receptor, this extracellular cytokine initiates several different signaling cascades resulting in the down-regulation of the important myogenesis genes. Muscle size is regulated via a complex interplay of myostatin signaling with the insulin-like growth factor 1/phosphatidylinositol 3-kinase/ Akt pathway responsible for increase in protein synthesis in muscle 14. Myostatin blockage or its natural absence leads to a significant increase in muscle mass [23]. Myotubes treated for $6 \mathrm{~h}$ with ATE showed a 4-fold downregulation of myostatin, supporting the putative anabolic effects of the plant. Methandrostenolone treatment also downregulated myostatin but to a lesser extent $(<2$-fold). These results are also compatible with other investigations. Gorelick-Feldman et al. studied the mechanism of action of ecdysteroids in murine $\mathrm{C}_{2} \mathrm{C}_{12}$ myotubes in which a $95 \%$ ethanol-based extraction preparation provoked a $15 \%$ increase in protein synthesis.

However, when myotubes were pretreated with a Phosphatidyl Inositol 3-kinase (PI3K) inhibitor, the effect on protein synthesis was significantly reduced indicating the involvement of this particular molecular pathway [11]. Knockout of the myostatin gene has been associated with the up-regulation of proteins involved in glycolitic shift of muscle and down regulation of proteins involved in oxidative energy metabolism. Specifically, investigators have found increased expression of genes belonging to the PI3K pathway in myostatin-null mice as opposed to the wild type [24]. Hence, down-regulation of myostatin by our ATE in $\mathrm{C}_{2} \mathrm{C}_{12}$ myotubes goes in accordance with previous published results.

Testosterone and other androgenic steroid drugs have been used in the past to increase or maintain muscle mass. These drugs act via the androgen receptors and as such have shown significant side effects that must be carefully evaluated before initiating any therapy. There is an increased risk for prostate hyperplasia and cancer in men, virilization in women, and cardiac hypertrophy and atherosclerosis for both [25]. Safer approaches have been evaluated as well. A randomized, double-blind, placebo controlled, multicenter trial was conducted to evaluate the safety and efficacy of a novel selective androgen receptor modulator (SARM). A total of 120 healthy men and postmenopausal women were evenly randomized to take placebo or $0.1,0.3,1$ or $3 \mathrm{mg}$ of SARM for 12 weeks. The incidence of adverse events was similar amongst groups with no serious events reported. Specifically, the novel compound did not have effects on sebum production or hair growth in women while eliciting a dose-dependent increase in total lean body mass, highlighting the benefits of dissociating the anabolic and androgenic activities when a therapeutic effect is sought [26].

The anabolic effect of ecdysteroids is connected with the acceleration of translocation processes instead of the induction of new RNA synthesis. Ecdysteroids are not likely to act as the classical steroids, via cytoplasmic receptor and regulation of gene transcriptional activity. In fact, an androgen dependent development is a prerequisite before the action of ecdysteroids in rats. Using radioligand assays Báthori et al. found that none of 11 tested ecdysteroids (including turkesterone) bound significantly to estrogenic, glucocorticoid or androgenic receptors [27]. Ecdysteroids display significant structural differences from anabolic-androgenic steroid hormones, which may explain the different mechanisms of their anabolic action.

MCF7-AR1 is a human cancer-derived cell line which has been genetically engineered to over express the AR [28]. The A-Screen cell bioassay, developed to measured anti-androgenic activity using MCF7-AR1 cell number as the end point, is used to identify androgenic chemicals among environmental pollutants and it has proved to be very sensitive and reproducible assay for detecting androgenic activity [29]. This assay measures androgendependent inhibition of proliferation of the androgen receptor (AR)-positive human mammary carcinoma cell line, MCF7-AR1. This cell line has been stably transfected with a full human AR and expresses approximately five times more AR than wild-type cells. MCF7AR1 cells retain the capacity to proliferate in response to estrogen treatment (E2). Androgens inhibit estrogen-induced proliferation and cells arrest in G0/G1 phase in a dose-dependent manner [28].

The A-Screen bioassay compares the cell number of similar inocula of MCF-7-AR1 cells growing in media in the absence of any estrogen and androgens $(\mathrm{C}-$-, negative control), in the presence of $\mathrm{E} 2(\mathrm{C}+$, estrogen control) and in the presence of E2 in combination with different concentrations of the suspected androgen (Figure 4). Androgenic activity of a test compound results in the inhibit-tion of cell proliferation compared to the E2 control. As expected both androgens (R1881 and Methandrostenolone) inhibited cell proliferation. However, adding ATE at a non-cytotoxic concentrations $(0.1-100 \mathrm{ppm})$ to the media did not show a significant proliferative inhibition compared with the control (MCF7-AR1 cells plus E2) (Figure 4(c)). Therefore and based on these results, it was established that our ATE does not show androgenic activity within the dose range used.

In conclusion, we have shown the feasibility of obtaining a standardized Ajuga turkestanica extract that retains the main bioactives in a ratio similar to that of the root material. Preservation of this natural ratio is essen- 
tial to maintain the synergistic effect of the different phytoactive compounds. Biological activity of the high content in ecdysteroids (and particularly turkesterone) of the ATE was demonstrated by real time qRT-PCR. Caspase-3 and Myostatin were both significantly down regulated, supporting the results by others which indicate ecdysteroids may protect against muscle waste. Results of the A-screen assay showed with high sensitivity the lack of androgenic activity of the ATE, a desired trait in developing alternative approaches for managing sarcopenia in humans. We believe further clinical work is warranted.

\section{Conflict of Interests}

José M Zubeldia, Aarón Hernández-Santana, Miguel Jiménez del Rio, and Verónica Pérez work for Polinat SL, the company which has developed and manufactures the Ajuga turkestanica extract. Jose Manuel García Castellano and Rubén Pérez Machin have no disclosures. This work was funded by Polinat SL.

\section{REFERENCES}

[1] M. H. Grace, D. M. Cheng, I. Raskin and M. A. Lila, "Neo-Clerodane Diterpenes from Ajuga turkestanica," Phytochemistry Letters, Vol. 1, No. 2, 2008, pp. 81-84. doi:10.1016/j.phytol.2008.03.004

[2] I. T. Abdukadirov, M. R. Yakubova, Kh. R. Nuriddinov, A. U. Mamatkhanov and M. T. Turakhozhaev, "Ecdysterone and Turkesterone in Ajuga turkestanica Determined by HLPC," Chemistry of Natural Compounds, Vol. 41, No. 4, 2005, pp. 475-476. doi:10.1007/s10600-005-0184-x

[3] N. Sh. Ramazanov, "Phytoecdyesteroids and Other Biologically Active Compounds from Plants of the Genus Ajuga," Chemistry of Natural Compounds, Vol. 41, No. 4, 2005, pp. 361-369. doi:10.1007/s10600-005-0153-4

[4] B. Z. Usmanov, M. B. Gorovits and N. K. Abubakirov, "Phytoecdysones of Ajuga turkestanica III. The Structure of Turkesterone," Chemistry of Natural Compounds, Vol. 4, No. 11, 1975, pp. 466-470.

[5] I. Machackova, M. Vagner and K. Slama, "Comparison between the Effects of 20-Hydroxyecdysone and Phytohormones on Growth and Development in Plants," European Journal of Entomolology, Vol. 92, No. 1, 1995, pp. 309-316.

[6] I. Soriano, I. Riley, M. Potter and W. Bowers, "Phytoecdysteroids: A Novel Defense against Plant-Parasitic Nematodes," Journal of Chemical Ecolology, Vol. 30, No. 10, 2004, pp. 1885-1899. doi:10.1023/B:JOEC.0000045584.56515.11

[7] H. Chiang, J. Wang and R. Wu, "Immunomodulating Effects of the Hydrolysis Products of Formosanin C and Beta-Ecdysone from Paris formosana Hayata," Anticancer Research, Vol. 12, No. 5, 1992, pp. 1475-1478.

[8] A. G. Kurmukov and O. A. Ermishina, "Effect of Ecdys- terone on Experimental Arrhythmias, Changes in Hemodynamics and Contractility of the Myocardium Produced by a Coronary Artery Occlusion," Farmakol Toksikol (Moscow), Vol. 54, No. 1, 1991, pp. 27-29.

[9] R. Lafont and L. Dinan, "Practical Uses for Ecdysteroids in Mammals Including Humans: An Update," Journal of Insect Science, Vol. 3, No. 7, 2003, pp. 7-36.

[10] V. Syrov, R. Sharapova and A. Kurmukov, "Effect of Ecdysterone on the Hematopoietic Activity on the Laboratory Animals with Experimentally Anemia," Issues in Obstetrics and Gynecology, Vol. 1, No. 1, 1976, pp. 6263.

[11] J. Gorelick-Feldman, D. Maclean, N. Ilic, A. Poulev, M. A. Lila, D. Cheng and I. Raskin, "Phytoecdysteroids Increase Protein Synthesis in Skeletal Muscle Cells," Journal of Agricultural Food and Chemistry, Vol. 56, No. 10, 2008, pp. 3532-3537. doi:10.1021/jf073059z

[12] T. Lang, T. Streeper, P. Cawthon, K. Baldwin, D. R. Taaffe and T. B. Harris, "Sarcopenia: Etiology, Clinical Consequences, Intervention, and Assessment," Osteoporosis International, Vol. 21, No. 4, 2010, pp. 543-559. doi:10.1007/s00198-009-1059-y

[13] P. Srikanthan, A. L. Hevener and A. S. Karlamangla, "Sarcopenia Exacerbates Obesity-Associated Insulin Resistance and Dysglycemia: Findings from the National Health and Nutrition Examination Survey III," PLoS One, Vol. 5, No. 5, 2010, p. e10805. doi:10.1371/journal.pone.0010805

[14] Y. Elkina, S. von Haehling, S. D. Anker and J. Springer, "The Role of Myostatin in Muscle Wasting: An Overview," Journal of Cachexia, Sarcopenia and Muscle, Vol. 2, No. 3, 2011, pp. 43-151.

[15] L. A. Burton and D. Sumukada, "Optimal Management of Sarcopenia," Clinical Interventions in Aging, Vol. 5, 2010, pp. 217-228.

[16] Y. Ohira, Y. Matsuoka, F. Kawano, A. Ogura, Y. Higo, T. Ohira, M. Terada, Y. Oke and N. Nakai, "Effects of Creatine and Its Analog, $\beta$-Guanidinopropionic Acid, on the Differentiation of and Nucleoli in Myoblasts," Bioscience, Biotechnology, and Biochemistry, Vol. 75, No. 6, 2011, pp. 1085-1089. doi:10.1271/bbb.100901

[17] R. E. Erb and M. H. Ehlers, "Resazurin Reducing Time as an Indicator of Bovine Semen Capacity," Journal of Dairy Science, Vol. 33, No. 12, 1950, pp. 853-864. doi:10.3168/jds.S0022-0302(50)91981-3

[18] S. Burattini, P. Ferri, M. Battistelli, R. Curci, F. Luchetti and E. Falcieri, " $\mathrm{C}_{2} \mathrm{C}_{12}$ Murine Myoblasts as a Model of Skeletal Muscle Development: Morpho-Functional Characterization," European Journal of Histochemistry, Vol. 48, No. 3, 2004, pp. 23-33.

[19] T. Kislinger, A. O. Gramolini, Y. Pan, K. Rahman, D. H. MacLennan, A. Emili, "Proteome Dynamics during $\mathrm{C}_{2} \mathrm{C}_{12}$ Myoblast Differentiation," Molecular \& Cellular Proteomics, Vol. 4, No. 7, 2005, pp. 887-901. doi:10.1074/mcp.M400182-MCP200

[20] N. S. Tannu, V. K. Rao, R. M. Chaudhary, F. Giorgianni, A. E. Saeed, Y. Gao and R. Raghow, "Comparative Proteomes of the Proliferating $\mathrm{C}_{2} \mathrm{C}_{12}$ Myoblasts and Fully Differentiated Myotubes Reveal the Complexity of the 
Skeletal Muscle Differentiation Program," Molecular \& Cellular Proteomics, Vol. 3, No. 11, 2004, pp. 1065-1082. doi:10.1074/mcp.M400020-MCP200

[21] X. H. Wang, L. Zhang, W. E. Mitch, J. M. LeDoux, J. Hu and J. Du, "Caspase-3 Cleaves Specific 19 S Proteasome Subunits in Skeletal Muscle Stimulating Proteasome Activity," The Journal of Biological Chemistry, Vol. 285, No. 28, 2010, pp. 21249-21257. doi:10.1074/jbc.M109.041707

[22] S. Bhatnagar, A. Mittal, S. K. Gupta and A. Kumar, "TWEAK Causes Myotube Atrophy through Coordinated Activation of Ubiquitin-Proteasome System, Autophagy, and Caspases," Journal of Cellular Physiology, Vol. 227, No. 3, 2012, pp. 1042-1051. doi:10.1002/jcp.22821

[23] S. J. Lee, L. A. Reed, M. W. Davies, S. Girgenrath, M. E. Goad, K. N. Tomkinson, J. F. Wright, C. Barker, G. Hermantraut, J. Holmstrom, B. Trowell, B. Gertz, M. S. Jiang, S. M. Sebald, M. Matzuk, E. Li, L. F. Liang, E. Quattlebaum, R. L. Stotish and N. M. Wolfman, "Regulation of Muscle Growth by Multiple Ligands Signaling through Activin Type II Receptors," Proceedings of the National Academy of Science US, Vol. 102, No. 50, 2005, pp. 1811718122. doi:10.1073/pnas.0505996102

[24] I. Chelh, B. Meunier, B. Picard, M. J. Reecy, C. Chevalier, J. F. Hocquette and I. Cassar-Malek, "Molecular Profiles of Quadriceps Muscle in Myostatin-Null Mice Reveal PI3K and Apoptotic Pathways as Myostatin Targets," BMC Genomics, Vol. 10, 2009, p. 196. doi:10.1186/1471-2164-10-196

[25] T. Thum and J. Springer, "Breakthrough in Cachexia Treat- ment through a Novel Selective Androgen Receptor Modulator?" Journal of Cachexia, Sarcopenia and Muscle, Vol. 2, No. 3, 2011, pp. 121-123. doi:10.1007/s13539-011-0040-8

[26] J. T. Dalton, K. G. Barnette, C. E. Bohl, M. L. Hancock, D. Rodriguez, S. T. Dodson, R. A. Morton and M. S. Steiner, "The Selective Androgen Receptor Modulator GTx-024 (Enobosarm) Improves Lean Body Mass and Physical Function in Healthy Elderly Men and Postmenopausal Women: Results of a Double-Blind, Placebo-Controlled Phase II Trial," Journal of Cachexia Sarcopenia Muscle, Vol. 2, No. 3, 2011, pp. 153-161. doi:10.1007/s13539-011-0034-6

[27] M. Báthori, N. Tóth, A. Hunyadi, A. Márki and E. Zádor, "Phytoecdysteroids and Anabolic-Androgenic SteroidsStructure and Effects on Humans," Current Medicinal Chemistry, Vol. 15, No. 1, 2008, pp. 75-91. doi: $10.2174 / 092986708783330674$

[28] J. Szelei, J. Jimenez, A. M. Soto, M. F. Luizzi and C. Sonnenschein, "Androgen-Induced Inhibition of Proliferation in Human Breast Cancer MCF7 Cells Transfected with Androgen Receptor," Endocrinology, Vol. 138, No. 4, 1997, pp. 1406-1412. doi:10.1210/en.138.4.1406

[29] A. M. Soto, J. M. Calabro, N. V. Prechtl, A. Y. Yau, E. F. Orlando, A. Daxenberger, A. S. Kolok, L. J. Guillette Jr., B. le Bizec, I. G. Lange and C. Sonnenschein, "Androgenic and Estrogenic Activity in Water Bodies Receiving Cattle Feedlot Effluent in Eastern Nebraska, USA," Environmental Health Perspectives, Vol. 112, No. 3, 2004, pp. 346-352. doi:10.1289/ehp.6590 